among others, to the pressure by the loosened cartilage on the layer of highly sensitive and vascular granulations springing from the inflamed or over-vascular bone. The patient cannot bear to have the joint jerked; he flexes the limb, in the case of the knee, that the lateral ligaments may be relaxed. The muscles hold the bones just in that position, with a spasmodic action, by which pressure is most avoided; and the sudden plunge and start, with the scream of pain, just when sleep is coming on, arise from the relaxation of the muscles at that moment, and the movement and jarring of the bones. No proper amount of rest can be obtained without a support; and the application of an instrument requires anatomical knowledge. To force the contracted limb into a straight position is an act of positive barbarity. For common purposes, a splint consisting of two iron cradles, one for the thigh, the other for the leg, united by a joint and screw, answers sufficiently well; but, in other cases, a more complicated apparatus may be required, by which not only flexion and extension, but abduction or adduction, may be obtained. The relief gained by taking off pressure from opposed ulcerating surfaces is often immense; and a little soothing treatment adds equally to the patient's comfort.

The consequences of constant motion letween parts so diseased as the denuded bones of a joint may be easily imagined. We should not expect to see an ulcer heal which we scraped once a day with a knife: how unlikely, then, are denuded bones to unite, when perpetually rubbing against one another: The cancellous texture of bone becomes so much inflamed that it dies, and separates in one or more irregular masses. In 1819 , a diseased knee was removed by amputation of the thigh, where the following morbid appearances were noticed. The patella was strapped tightly to the outer condyle, with which it formed a distinct articulation. The articular cartilage was removed by absorption, and the surface of the bone was rough. Upon the surface of the outer condyle of the femur a small bit of dead bone was seen imbedded in the cancellous structure of the femur. The ligaments of the knee-joint were entire, but softened; the anterior crucial ligament readily gave way; the semilunar cartilages were absorbed. Upou the inner condyle, the surface of the bone was denuded of articular cartilage; it was rougher and denser than natural. The cuter condyle of the tibia presented a disc-like surface, of ivory-like hardness, denuded of cartilage, and surrounded by a ragged border, indicating the situation of the semilunar cartilage. The corresponding surface of the femur was rough, and denuded of cartilage. Two pieces of dead bone were imbedded in the cancellous structure of the head of the tibia, one of which lay in a cavity containing pus.

No doubt can be entertained that many of these changes were due to the want of rest between the diseased surfaces of bone. The outer surface of the tibia rubs, in the natural movement of the knee, against the corresponding surfaces of the onter condyle of the femur, in rotation outwards, in the flexed condition of the leg; the inner articulating surfaces acting as the pivot. This is what takes place when the heel is turned inwards in spurring, etc. The rotatory movement seems to have made the surface of the tibia as hard as ivory, while in the proximity were the common indications of inflammation of hone, abscess, and necrosis.

In former times, amputation was even more extensively em. ployed for diseases of joints. The remedy was not calculated to become popular. Resection is now in vogue, claiming as its patron the spirit of conservative surgery. I affirm that the attractions of the operating theatre have induced surgeons to neglect the study of orthopædic appliances. Such means have not been tried with half the zeal which has been manifested in the cause of the linife. I know of two cases at the present time, one under the care of Mr. Tamplin, the other treated by the late Mr. Lonsdale, in both of which the knee-joint was condemned. Both patients have been relieved by other means, and can now use the diseased limb with a freedom which secures the power of easy locomotion.

CASE IV. A young girl, educated for a governess, caught cold in 1853, being at that time sixteen years of age, and suffered from an attack of rheumatic character. In December 1855 a second attack ensued in consequence of cold brought on by wet feet, and the rheumatism settled in the right knee, which become much swollen. Hot fomentations, leeches, blisters, etc., were ordered, and under proper treatment the pain and swelling subsided, but the leg remained stiff and contracted. The knee was then strapped and rolled for a fort. night; but, no benefit ensuing, frictions with a stimulating liniment were employed; this was followed by warm fomentation with salt and water, which was continued until the begin- ning of the summer of 1857 , when all treatment was discontinued, and further advice was recommended. During the time when the pain and swelling were at their height, the removal of the limb by amputation was recommended in con. sultation. This measure was very properly declined.

She was admitted into the Royal Orthopædic Hospital under Mr. Tamplin. She is a well made and healthy-looking girl, but of naturally pale complexion. The state of the right lower extremity constitutes her only complaint. The tibia and fibula of that side are dislocated backwards and outwards from the lower extremity of the femur; the tendon of the biceps flexor cruris muscle is tense; the leg is firmly bent to a right angle on the thigh; the patella bound down upon the outer condyle of the femur; but the soft parts composing the joint are in a quiet state; there is neither heat nor swelling; sufficient motion exists between the bones to show that osseous anchylosis (always a rare occurrence) has not taken place. The apparatus for slow extension was applied.

Jan. 4 th, 1858. The leg is so much straighter that she can support herself upon it; she is free from pain, and has every prospect of possessing a perfectly useful limb.

Jan. 22nd. She still wears the instrument, but the leg is coming into good position.

CASE v. Mary Anne H., aged 22, is at the present moment under my care in St. Bartholomew's Hospital on account of a diseased condition of the left knee. She states that when quite a child the knee-joint became swelled and painful after a sprain; that she was a long time under treatment; and that she remembers a recommendation and proposal that amputation should be performed at the thigh. The whole limb is smaller than the opposite; the leg is bent upon the thigh; and the tibia and fibula are drawn backwards and outwards from the articulating extremity of the femur into the popliteal space. The tendons of the hamstring muscles are tense. She walks with a single crutch, the toes of the affected side being six inches from the ground. I divided the tendons of the biceps flexor cruris; and directing the girl to lie in bed, applied weights to the foot, commencing from three pounds and reached seven, by means of a cord and pulley. In the course of three weeks I have obtained elongation of the limb to the extent of four inches, and the patient, for the first time since infancy, is able to walk unaided, and without the use of the crutch. I hope still to obtain further lengthening of the limb; and this would be the case without fail, were there all the appliances, such as are attainable in private life. But in the present condition the patient was admitted a cripple, and unfit to follow any useful occupation; and she will be enabled, with the assistance of a high-soled shoe, to discard her crutch, and walk from the hospital with sufficient activity to gain some employment by which she can earn a livelihood.

\section{THE METEOROLOGY OF 1856 AND 1857.}

\section{By J. A. Hivgreston, Esq., Brighton.}

THE meteorological phenomena of 1856 and $185 \pi$, so far as they relate to the public health, may be grouped into a single tableau, comprising a consecutive chain of events. As the fatal year of 1854 was not less remarkable for its epidemic than for its atmospheric peculiarities, so the three following years, from 1855 to 1857 , were no less remarkable for their salubrity; and, with a few exceptions, the regularity of their seasons. During their course, cholera was absent altogether as an epidemic; the south-westerly winds prevailed, the temperature was normal, and the rain-fall sufficient. The meteorology of 1854 was published in the Association MEDICAL Journal, No. CXI, February 16th, 1855, p. 151; and that of 1855 , in the same Jounsal, No. CIX, January $26 \mathrm{th}, 1856$, p. 66 : and I now proceed to draw up a summary of the years 1856 and 1857 , from daily records of my own as well as from those of the Astronomer Royal, at Greenwich, published in the Regis. trar-Gencral's Weelily Returns of Deaths, etc.

The winter of 1856 was generally mild. Snow fell on three days in February, the 20th, $2: 3 \mathrm{rd}$, and remained upon the ground for only one day, the 21st. Upon the quarter ending Iarch 31st, the temperature was somewhat in excess; the air was very moist, though the barometer indicated dry weather, and the equinox was calm. The spring was cold and wet. Aprii, indeed, was congenial, and suitable to farming operations; but Mlay set in with rigour, being $4^{\circ} \mathrm{Fah}$. less than its arerage. The niglits were chilly, and the grass and young crops suffered in consequence. The 3lst was $9^{\circ} \mathrm{Fah}$. below 
the average of the season. Thunderstorms were frequent, as well as strong gales of wind and rain; and the spring, which had opened with such excellent promise, closed unfavourably to the haymakers, gardeners, and florists. The apple trees and wall-fruits were utterly blighted. The bees were unable to set the blossoms. There were dark mists, and flights of small black flies. Between January lst and June 30th, there were as many as fifty-six days of fog, mist, or haze, or about one-third of the whole period. July was also dark, misty, and cold. There were some short intervals of excessive heat; the thermometer standing at $102^{\circ} \mathrm{Fah}$. in the sun, and $75^{\circ} \mathrm{Fah}$. in the shade, on June 27 th and $28 \mathrm{th}$; and there was another scorching interval from July 30th to August 1lth, when the thermometer rose to $113^{\circ}$ Fah. in the sun, on the 2 nd of the latter month. But Augrust closed with mists and a damaged harvest.

But at this time the weather cleared up, and the next sixteen months that followed were uninterruptedly seasonable and pleasant. From September 1856 to December 185\%, every thing proceeded well. The temperature was at the average of the respective seasons. The autumn of 1856 was fine and open. The winter began early with a fall of snow on Novem ber " 6 th, and ice formed upon the ponds to the thickness of three or four inches. The greatest cold in the night was $20^{\circ}$ Fah. There were some interruptions to the frost and snow. 'The end of the old year, 1856, and the beginning of the new, 1857, were mild; but the frost set in agair on January 16 th, and the snow lay upon the ground from the 24 th of this month till February $11 \mathrm{th}$. The greatest cold in the night was $22^{\circ}$ Fah. The weather continued wintry and frosty, with occa sional falls of snow, till the middle of March, when the spring suddenly opened, and the winter disappeared. The trees budded, and the swallows returned early; and from April 29th till November 29th following, there was not a single frosty night, so frequent in this country, even at midsummer. The sky was blue, and chequered with clouds. The cirri were numerous. The mornings and evenings were delightful. The nights were starlight, and the temperature was equable. Though June was remarkable for its intense heat, the 28 th of that month lieing the hottest day we have experienced since Jul lith, 1816; yet the heats of summer were not oppressive, and we were allowed to enjoy the splendour of a tropical climate, without heing exposed to the imminent perils of the tropics. The fruits were abundant, the cereals excellent, and the cultivation of the land propitious. The antumn was particularly pleasant, and the close of the year mild, bright, and cheerful.

The amount of rain-fall in 1856 was 12.06 inches in the first six months, and 15.20 inches in the last six: which was rather above the average. In 1857 , the rain-full measured 25.8 inches, or about the arerage. The last six were as usual wetter than the first six months. The driest were February, June, and Decomber. August was among the wettest, and October the wettest of all.

The S.W. winds blew one hundred and sixty-four dars in 1856 , or more than half the year ; and in $185 \%$, for two hundred days, or nearly two thirds. In 18,44 , the year of the cholera the prevailing winds were N., F., S. But, storms apart, the movement of the air, although continual, has not been stron cluring the past year; for the millers inform me, that they have been able to work their wincmills less this year than in mos others. On the 7 th and 8 th of October, there was one of those severe storms, from the S.W. S, which Humboldt calls mognetic. 'The magnet was disturbed several days previously, and a long streak of cloud passed from S. to $N$., in the line of the magnetic meridian, before the storm burst. The barometer fell to 28.790 inches. The force of the wind, as estimated by Whewell's anemometer, at Greenwich, was represented at the rate of 205 miles in the dar.

The hitrest of 1856 was late, and badly got in, owing to the dampress of the weather; hut in 185\%, the crops were univer sally good and abundant, and the reaping unusually early and complet.

The niteteorologieal conditions appear to have been generally favourable to health. The mortality during the first half of 185 ( ; was below the average in the proportion of 21 to 23 per 100() , and the virths were at the same time unprecedentedly high. 'The natural jucrease of the population from diminished draths and incrased marriages in the first quarter of 1856 was according to the Registrar.Cieneral's Guarterly Returns, no fewer than 6id,014 in England alone; and in the last quarte of 1850 , the moriality sank as low as 20 per 1000 per annum. in the first quarter of 18.37 , the natural in rease of the popula tion of the United Kingdom was calculated to be at the rate of
1000 a-day; while in the second quarter it probably exceeded 1100 a-day; and the same ratio of increase was recorded till the close of the quarter ending September 1857. (See Quarterly Returns of Marriages, etc., published by authority of the Registrar.General, 1857, No. 33, p. 2 ; and also No. 34, p. 2 .)

During these two years, there have been several atmospheric and telluric phenomena deserving of notice. On January 6 th, 1856, there was a meteor, at surset, visible at Rouen, in France, and at Knolles Park, in Wales, at the same time, giving a base line of 250 miles, and, by triangulation, its approximate altitude was found to be sixty miles above the earth's surface at least; and on December 17th, 1857, another meteor was visible at the same time at Durham and at Brussels, giving a base-line of 400 miles, and consequently an enormous elevation of the fiery globe above the earth, probably not less than 150 miles. The size of these two meteors must have been something prodigious.

On Octcber 12th, 1856, there was an eclipse of the moon. As the earth's shadow passed over her surface, the darkened portion of her disk became of a reddish tint, with a pale green edging. An unpleasant twilight pervaded the land and sea, and the stars shone with a faint and sickly splendour through the gloom. It was on this night that the shock of an earthquake was experienced at Malta.

Several earthquakes were reported in these two years. The Punjaub was visited by a succession of them, and the first shock was felt at Lahore on Sunday, May 9th, 1856. It caused a feeling of sicliness. The weather was sultry. On Wednesday, June 25th, there was a shock at Adelaide, in South Australia; and Last Island, in the Gulf of Mexico, was submerged and entirely covered with the sea about the same time, and seventy. five lives were lost. On October 12th, a very severe one was felt in the Mediterranean, extending from Calabria, in Italy, to the island of Rhodes; and its focus seems to have been about Rhodes and Candia; at the latter place, 500 mangled corpses were dug out of the ruins, and not more than fifty houses remained uninjured. It was felt at Macri, on the coast of Asia Minor, opposite Rhodes, and at Beyrout, in Syria. It stopped the pendulums of the Roval Observatory at Palermo. 'The barometer stood at 30.201 inches. There was a fog at the time. 'The English steamer, St. Andrev's, felt the shock at sen, 300 miles from Rhodes, and sprung a leak. A deluge of rain followed. The sentries at Maltu reported a red glare in the heavens, and the dogs howled previous to its occurrence. On the night of December 17th, 1857-the night of the meteor seen at Brussels and Durham-a violent earthquake shook the kingdom of Naples. Its focus seems to have been at Salerno. It extended as far as the coast of Africa on the south, Croatia on the east, and Bavaria and Sweden on the north. The shocks were repeated for several days afterwards. Many other towns, Polla, Polenza, and Sola, besides Salerno, suffered greatly houses being thrown down, and the earth rent in twain. It destroyed 14,000 lives, at the lowest computation. Lesser shocks were felt at sundry places : at Constantinople, in February 1856 ; at Sedge Hill, Wilts, in England, in March 1857 ; and at Aix la Chapelle, and Coire, Grisons, about the middle of June, in the latter year.

Vesuvius was in action throughout $185 \%$, but chiefly during the summer and autumn. In the beginning of 1856 there was a volcanic eruption of some violence from a mountain called the Mauna Loa, 1,200 feet above the level of the sea, in the Sandwich Islands. Near the Azores, the master of the British schooner Estramadura, of Glasgow, reported an eruption of hot vapour from the sea, on a clear day, November 25 th, $185 \%$. In Central America, as well as along the mighty chain of the Andes, and also in the volcanic groups of islands in the Southern Ocean, the volcanoes have been continually at work.

That the action of internal fire, thus manifested by volcanoes and earthquakes, powerfully modifies the temperature of the air and its barometrical pressure, there can be no doubt. It is not possible that a large funnel, such as that of Vesuvius, should continue emitting vast bodies of flame and red hot lava, without diffusing a very great amount of heat extensively throughout the upper regions of the atmosphere; and the heated gases that escape from fissures in the rocks produced by earthquakes, or the boiling vapours forced from the depths of ocean by the same stupendous agency, cannot fail to help in producing the same effects. From some observations that $\mathbf{I}$ have made, but too long to be narrated here, it appears to me that changes of temperature are due as much to the earth itself, in its capacity of a globe charged with caloric, both latent and free, as to the air we breathe, or the sun's rays by which we are warmed and lighted. Certain it is that the heat, measured 
by a thermometer, with its ball two feet below the earth's surlace, by no means corresponds with the variations of the air above; indeed, its variations seem to be influenced by causes of its own; and such may be the case. For the earth, besides being the magnet in chief, is the largest of electrical bodies; while its interior is evidently a laboratory alive with elements perpetually undergoing their electro-chemical changes on a gigantic scale, and producing results of which volcanoes and earthquakes are but partial, though enormous, phenomena. The magnetic and electro-chemical action of the earth itself, on the health of mind and body, must be as powerful as it is constant and immediate.

Spots appeared in the sun in March, and gradually increased in number and size as the year went on. They recur about very eleventh year in a century, and are supposed to be coinident with a hot summer : 1846 was hot, so was 1835 , and so were also 1824 and 3813 .

The Asiatic cholera was reported from the Crimea and Vienna in the spring of 1856 , and a fow solitary cases were re$\because$ orded in the Registrar.General's returns, but it was not rife in the United Kingdom throughout the whole of that year. It was the same in 185\%. A few cases were reported in August and September, but the disease never gained ground, and in each case it might be attributed to local causes or infection from the Continent; for it prevailed in Hamburg, on the Elbe, as at Glückstadt, for instance, and along the shores of the Baltic, from Finland and Denmark, to St. Petersburg, in August and September; but the British isles were entirely free from it in its epidemic form. The second week of September, hitherto its worst period in this country, showed a gradual diminution of cases, which had been on the increase during the two preweding months; and it must be observed that the weather, peculiar to the cholera, had been altogether absent both in 1856 and 1857; thus affording a negative proof of the coincidence of atmospheric peculiarities with the rise, progress, and decline of the disease.

Should the morbific condition of the air, which seems to be its efficient cause, cease altogether, there is every reason to suppose that the disease would cease also, and that the Asiatic rholera, the dreaded pest of recent years, would, like former epidemics, at length vanish from the earth, and be remembered only among the data of the past. Should the north-westerly winds from the Baltic and the north of Germany, which have always prevailed in cholera periods, loaded as they are with chilly vapours, snow; or drizzling mists, give place to the more genial gales from the south-west, warm from the gulf of Mexico, for several summers in succession, I cannot forbear from expressing my conviction, that the Asiatic cholera would not recur fluring such favourable seasons, but would, were such seasons continued long enough, at last disappear from Europe, and, in fine, never be heard of again in the western hemisphere.

\section{Climital apecture}

\author{
DEITVERED IN THE
}

\section{QUEEN'S COLLEGE, BIRMINGHAM,} ON JANUART $16 \mathrm{TH}, 1858$.

By Joseph Sampson Gamaee, Esq., Surgeon to the Queen's Hospital.

RUPTURED PERINEUAI OF OLD STANDING: WOUND OF RADIAT, ARTERY AND WRIST-JOINT : SCROFULOUS DISEASE OF KNEE-JOINT: GENERAL REFLECTIONS.

Gentlemen,-The cases which I am about to bring before you have already been the object of our conversations at the bedside. As they illustrate important therapeutic principles in some of the commonest surgical affections and injuries, the observations I am about to make may not be the less profitable, though to some extent a repetition. I cannot sufficiently commend to you the reiterated contemplation of simple cases, the foundation of the most generally useful knowledge.

Case r. Ruptured Perincum : Procidentia Uteri : Partial Rectocelc and Cystocele. Jane Stephens, aged 32, was admitted in No. 1 Adelaide Ward, last December. For years, she has been an out-patient at the Queen's Hospital for scrofulous lisease. She married thirteen years ago; her first confinement, a year afterwards, was difficult; labour lasted seventy. two hours; instruments were employed. The third day after delivery, while being moved from her bed into a chair, she "felt something give way", as though the inside was dropping through. At the same instant there was a gush of blood. On the tenth day, she left her bed, and shortly resumed work. The womb gradually descended, and made its appearance ex ternally in the ninth month; the protrusion has continued to increase.

On admission, she complained of pain in her loins and down the thighs; and of pain and difficulty-often very great-in defecation. Sometimes micturition was impossible, unless the uterus were pushed back.

You doubtless have a clear recollection of the large size of the vaginal orifice, from which a pear-shaped lump as big as my tist protruded; its surface was skinny; and on the face of its lower and broadest end you saw the transverse opening into the uterine cavity. I showed you how the catheter passed into the urethra did not go upwards and backwards as in the normal condition, but passed downwards and forwards on to the front of the tumour; my finger, introduced into the rectum could with ease be turned forwards and downwards, and its end was readily perceptible at the under surface of the pro truding womb.

The poor woman was quite unable to support the organ in its natural position; and she implored relief.

Diagnostically, a more simple case could not be imagined. The perinæum had been ruptured to within a quarter of an inch of the rectum, so as to enlarge the vaginal aperture, and admit of the protrusion of the womb, easily distinguishable by its size and shape, and by its relations with the bladder and rectum, which were also partially displaced, as a mechanical result of the traction exercised upon them. As a typical case of such injury, the one under consideration might be profitably studied under all its bearings; but time will not allow us to do so at present, and therefore I shall limit myself to convey to you the reasons which led me to do something in compliance with the poor woman's request for relief. I shall recall to your memory the steps of the operation performed, examine its results, and endeavour to anticipate the final issue.

The patient's suffering and discomfort were considerable: for obvious mechanical reasons, they would go on increasing. Recorded surgical experience proved that an operation might be undertaken with a palliative intent, with a great probability of success, practically with no danger to life, or of aggravating the local mischief, if the attempt at relief failed. That attempt consisted in contracting the vaginal orifice, so as to prevent protrusion of the womb. With this view, the patient was placed on the operating table in the lithotomy position; the uterus was pushed back; the bladder emptied, the bowel having already been relieved of its contents. A strip, about three-fourths of an inch wide, of mucous membrane and contiguous skin, was dissected from the posterior two-thirds of the vaginal aperture, in a horseshoe shape. No vessel required tying. The cut surfaces were approximated by three loops of quilled suture, and the edges of the skin with five points of interrupted suture: apposition was perfect, but a few drops of blood were lost. You noticed how deeply I passed the long handled needle bearing the loops of twine which were on each side firmly tied over the piece of bougie. With a probe-pointed bistoury, I divided the fibres of the sphincter ani on each side, so as to keep that little muscle quiet. The patient was carried back to bed, and laid on her left side, with the thighs semiflexed and tied together. There was nothing original in this proceeding, founded on the first rudi ments of plastic surgery. In dividing the sphincters, I fol lowed the example of Mr. Baker Brown, who, after Roux and Dieffenbach, has done much to generalise this plan of treatment.

The after treatment was simply but efficiently conducted by Mr. Allis Smith, the house-surgeon. The urine was drawn off by catheter several times daily, to prevent its trickling into the wound, and to avoid effort. Opium was freely administered, to keep the bowels quiet. The middle loop of the deep sutures was cut on the fourth day, but not until the tenth were all the sutures removed. Only slight fever supervened. Locally, all proceeded satisfactorily; and you now see that union was perfect throughout the whole extent, superficially and deeply; and the woman has a good perinæum of average depth. The uterus can be felt just within the vaginal orifice, and does not protrude when the woman walks about with the support of a $\mathrm{T}$ bandage. It protruded, however, to a slight extent, during efforts at defæcation, the day before yesterday. I purpose further diminishing the size of the orifice by snipping off some redundant 